\title{
A special price just for you: effects of personalized dynamic pricing on consumer fairness perceptions
}

\author{
Anna Priester ${ }^{1} \cdot$ Thomas Robbert $^{1} \cdot$ Stefan Roth $^{1}$
}

Received: 1 April 2019 / Accepted: 31 October 2019 / Published online: 23 January 2020

(c) The Author(s) 2020

\begin{abstract}
Personalized dynamic pricing (PDP) involves dynamically setting individual-consumer prices for the same product or service according to consumer-identifying information. Despite its profitability, this pricing provokes strong negative fairness perceptions, explaining why managers are reluctant to implement it. This research provides important insights into the effect of two PDP dimensions (price individualization level and segmentation base) on fairness perceptions and the moderating role of privacy concerns. The results of two experimental studies indicate that consumers perceive individual prices as less fair than segment prices. They also evaluate location-based pricing as less fair than purchase history-based pricing. Consumer privacy concerns moderate these effects.
\end{abstract}

Keywords Personalized pricing $\cdot$ Fairness perceptions $\cdot$ Privacy concerns $\cdot$ Dynamic pricing

\section{Introduction}

Recent advances in information technology have given online retailers the ability to identify and track individual consumers on the Internet in real time and at virtually no cost. Combined with the availability of new automated algorithms, the personalization of prices has increasingly become a sound pricing option in the online environment. For example, ZipRecruiter, an online employment marketplace, indicates that it could increase profits by $84 \%$ by experimenting with personalized prices (Wallheimer 2018). Other players, such as travel sites (e.g., Orbitz, Hotel Tonight; DeAmicis 2015; Mattioli 2012), retailers (e.g., Amazon.com, Home Depot, Staples; Streitfeld 2000; Valentino-DeVries et al. 2012), and even grocery stores (e.g., Safeway; Clifford 2012) have also reportedly begun implementing personalized prices for their customers based on individual characteristics.

Anna Priester

anna.priester@wiwi.uni-kl.de

Thomas Robbert

robbert@wiwi.uni-kl.de

Stefan Roth

roth@wiwi.uni-kl.de

1 Department of Marketing, TU Kaiserslautern, P.O. Box 3049, 67653 Kaiserslautern, Germany
The new pricing instruments represent an important strategic potential for online retailers. Although these instruments can be highly profitable (Lee et al. 2011), given their potential to extract higher shares of consumer surplus (Carroll and Coates 1999), retailers have only just begun implementing this pricing practice comprehensively (Borgesius and Poort 2017). A possible reason retailers are still reluctant to do so is the fear of consumer backlash if customers become aware of its implementation.

The general idea of differential pricing is not new and has been investigated in multiple fields, including marketing (Dhar and Hoch 1996; Narasimhan 1984), economics (Pigou 1929; Thisse and Vives 1988), and public policy (Kochelek 2009; Miller 2014). More recent research has particularly focused on dynamic pricing. In its traditional sense, this form of intertemporal price discrimination entails price changes over time due to fluctuations in supply, demand, competition, or other factors (Krämer et al. 2018). Prices thus vary depending on the time of purchase but are the same across consumers at a given time (Abrate et al. 2019). Personalized dynamic pricing (PDP) also involves sellers dynamically setting prices for the same product or service across different consumers with the aid of consumer-specific data such as IP address, purchase or browsing history, or other consumer-identifying characteristics (Richards et al. 2016). PDP is therefore regarded as a special form of dynamic pricing. 
In light of the rising debate on consumer data privacy and the fear of incidents of unwanted privacy invasions and data fraud (Awad and Krishnan 2006; Martin and Murphy 2017; Smith et al. 2011), it is surprising that the role of privacy concerns in PDP has not been a topic of academic discussion. Yet research indicates that consumers perceive PDP as less fair than price differentiation that depends on time of purchase (Grewal et al. 2004), purchase quantity (Lii and Sy 2009), an active price-setting mechanism (Haws and Bearden 2006), or seller choice (Garbarino and Maxwell 2010). With regard to the profitability of PDP, Wittman and Belobaba (2017) are able to demonstrate that implementing heuristics that enable personalized fare offers have a positive impact on the revenue of an airline in the context of revenue management. In addition, research has discussed legal and ethical concerns of consumers (Turow et al. 2015) and the fear of eroding data privacy (Borgesius and Poort 2017).

Yet, to date, a comprehensive picture of the consequences of PDP on consumer reactions is missing. In this paper, we argue that current research is still ambiguous regarding different characterizations of PDP, and thus the topic lacks a thorough investigation. We propose to characterize PDP systematically through two dimensions. First, as noted, with PDP, sellers assign prices for the same product or service across different consumers using consumer-specific segmentation bases. Second, PDP can vary in its price individualization level. Depending on the availability and quality of underlying data, prices can range from individual prices for each consumer to segment prices for larger consumer segments.

From a management perspective, this distinction is important because online retailers need to understand which segmentation base is best suited for their offerings. Profound knowledge on the perception of different segmentation bases and individualization levels is important not only to explore customer surplus but also with regard to possible downstream effects such as fairness perceptions. Managers need to understand if and what difference in consumer behavior occur when they set prices individually versus for an entire customer segment. In addition, they need guidance on whether to set prices on location data, purchase history, or any other segmentation base. Parallel to this, insight into PDP is relevant for consumer advocates and public policy makers as they strive to understand whether PDP will disadvantage consumers and whether the use of individual consumer data for price calculation should be allowed.

Given the depicted research gaps and their importance for managerial practice, the current research aims to unveil (1) how consumers perceive individual prices compared with segment prices, (2) how they perceive PDP under varying segmentation bases, and (3) the role of privacy concerns in the perception of fairness. In particular, this study aims to shed light on the role of two frequently used segmentation bases. The first segmentation base we chose is one that has recently gained increasing importance through mobile devices, including GPS features (location data), and the second is one that has already been commonly used (purchase history). In addition, we investigate possible interaction effects that arise with two segmentation levels: individual and segment prices.

In Study 1, we focus on the price individualization level by comparing individual and segment prices while keeping the segmentation base constant (location data). In Study 2, we extend the previous study by including the second segmentation base (purchase history). In addition, we examine whether the effects vary depending on consumers' level of privacy concerns. The results of our empirical studies indicate the importance of these two bases. Both dimensions have significant effects on consumer fairness perceptions independent of each other. Previewing our findings, we show that a more granular price individualization level negatively affects consumers' fairness perceptions. In addition, consumers have lower fairness perceptions of pricing based on location data than pricing that depends on their purchase history. Consumer privacy concerns act as a moderating variable for both effects. Consumers with low privacy concerns even perceive individual pricing as fairer than segment pricing. By contrast, consumers with high privacy concerns evaluate individual pricing as less fair than segment pricing. In addition, these consumers do not perceive location-based pricing as less fair than purchase history-based pricing.

This research contributes to the academic discussion in three important ways. First, it provides a clear characterization of PDP by distinguishing between consumer-specific segmentation bases and price individualization level. Second, it gives a structured overview on the current state of the art of literature on interpersonal price discrimination and PDP and uncovers research gaps that have not yet been subject to investigation. Third, it extends previous research on consumer perceptions of interpersonal price discrimination (Wu et al. 2012) and PDP (Krämer et al. 2018) with two empirical studies. In addition, this article is the first to analyze consumer privacy concerns in the context of PDP. Thus, it adds to the work of Miller (2014) and Odlyzko (2003), who conceptionally underscore consumers' increasing concerns about the collection and usage of their personal information for pricing.

\section{Research background}

\section{PDP and fairness perceptions}

Fairness perceptions are an integral determinant of consumer price perception (Xia et al. 2004) and price acceptability (Lichtenstein et al. 1988). Consumers form their fairness 
perceptions on whether an outcome or process can be deemed reasonable, acceptable, or just (Bolton et al. 2003). This assessment relies on the comparison of own outcomes with another reference price (Xia et al. 2004). Reference prices can be conceptualized as either expectation-based price or "fair" price (Monroe 1973; Viglia and Abrate 2014). An expectation-based price relies on a consumer's past experience or current purchase environment (Kalyanaram and Winer 1995; Mazumdar et al. 2005), while a fair price is a normative price indicating what price is considered "fair" for a seller to charge (Bolton et al. 2003). Reference prices in the sense of fair prices often result from social comparisons, such as the prices other consumers paid (Xia et al. 2004). In the presence of multiple reference points, consumers tend to rely on social comparison rather than past experience to form their fairness judgments (Choi and Mattila 2004). The current research therefore follows the conceptualization in the sense of a fair price.

Various consumer-identifying segmentation bases can aid sellers in implementing PDP. Furthermore, previous research often attributes PDP to first-degree price differentiation (Choudhary et al. 2005; Garbarino and Lee 2003). According to economic literature, price discrimination can be divided into first, second, and third degree: first-degree price discrimination applies when sellers set individualconsumer prices; second-degree price discrimination gives consumers the possibility to self-select predefined price segments; and third-degree price discrimination implies that sellers differentiate prices based on predefined price segments without the possibility of self-selection (Pigou 1929; Varian 1989). Yet both the first and third degree correspond to price discrimination, in which prices are determined by the seller on the basis of consumer characteristics. Aydin and Ziya (2009) suggest that the ability to personalize prices is dependent on the data a retailer has on its consumers and, on that basis, the possibility to make inferences about consumers' willingness to pay. Given this reasoning, PDP cannot be clearly assigned to either first- or third-degree price discrimination. Depending on the quantity and accuracy of available data, PDP can thus vary in its price individualization level-it is more or less individually identifying. Sellers can either set prices for individual consumers or, if the data do not allow for more unique identification, set prices for consumer segments (Aydin and Ziya 2009). Ideally, if the data quality is high, PDP can be used as first-degree price discrimination, while PDP virtually resembles third-degree price discrimination in the case of less identifying data. In the following paragraphs, we refer to PDP as 'individual pricing' in the sense of first-degree price discrimination and as 'segment pricing' in the sense of third-degree price discrimination. Furthermore, while some authors include consumers' active participation in the price-setting mechanism under PDP (Haws and Bearden 2006; Richards et al.
2016), we limit our perspective of PDP to posted prices by the seller.

Although PDP can range from individual to segment pricing, the literature does not take sufficient account of this differentiation. Most extant research analyzes only how consumers perceive price discrimination on a consumer segment level. To assess consumer fairness perceptions, these studies analyze how consumers evaluate price differences between different consumer segments compared with other sources of price discrimination. In that regard, Haws and Bearden (2006) find that consumers perceive price differences between individual consumers as less fair than price differences between different purchase times or different sellers; however, Haws and Bearden do not explicitly define the segmentation base of interpersonal price discrimination. Conversely, other research analyzes the perception of price discrimination based on consumer loyalty status. For example, Garbarino and Maxwell (2010) find that consumers evaluate pricing based on loyalty status as less fair than price differences between different sellers. Lii and Sy (2009) show that consumers perceive price differences based on loyalty status as less fair than price differences based on purchase quantity and purchase time but fairer than price differences between different channels. Grewal et al. (2004) support the finding that pricing based on purchase quantity produces higher fairness perceptions than price differences between consumer segments. Their findings also reveal that consumers show higher fairness perceptions of a pricing method in which loyal (vs. new) customers receive a price advantage, which is in line with social norms. Huang et al. (2005) and Wu et al. (2012) also investigate price discrimination based on segment level but, in contrast with other studies, include the analysis of several different interpersonal segmentation bases. Huang et al. (2005) show that consumers judge discounting to loyal customers as fair. They further investigate geographic discrimination and find that consumers evaluate it unfair. In the same vein, Wu et al. (2012) show that interpersonal price differences, which consumers perceive as violating norms (pricing based on residential area), produce the lowest fairness perceptions while norm-compliant price differences between consumers (pricing based on student/senior status) cause the highest fairness evaluations. Price differences between consumers that hold the option of consumer self-selection (pricing based on coupon redemption, membership status, or purchase quantity), in turn, rank between the norm-violating and norm-compliant pricing. Krämer et al.'s (2018) recent study extends previous findings by investigating price differences resulting not only from segment pricing but also from individual pricing. Their results reveal that consumers evaluate price differences between individual consumers (based on customer profiling) as less positive than price differences between different consumer segments (based on frequency of usage). Table 1 


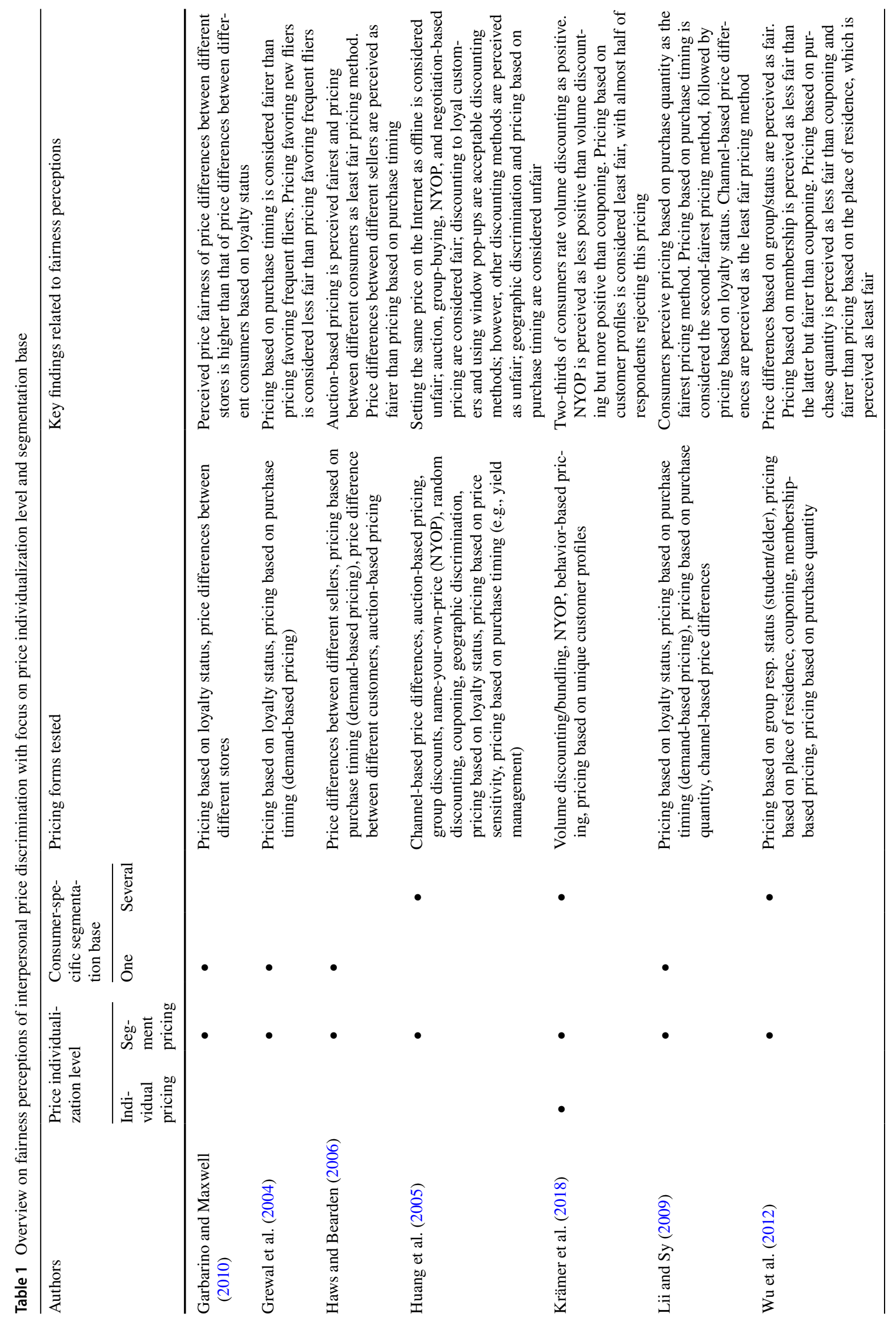

唀 
provides an overview of these studies, depicting the price individualization level analyzed in the studies and whether the studies investigated different consumer-specific segmentation bases.

In summary, most studies analyze consumer fairness perception of only one consumer-specific segmentation base. The few studies that investigate the perceptions of several consumer-identifying segmentation bases, however, focus on the price individualization level of consumer segments only. Moreover, studies take even less account of the price individualization level. Except for Krämer et al.'s (2018) study, all previously mentioned studies only analyze different forms of interpersonal price discrimination on the segment level. Krämer et al. (2018) also examine consumer price perception of both different price individualization levels and different interpersonal segmentation bases; however, their analysis does not provide insight into possible interaction effects between these variables.

In addition to norm compliance (Garbarino and Maxwell 2010; Wu et al. 2012), research has revealed several other factors that influence the effect of interpersonal price discrimination on consumer fairness perception. For example, consumers show higher fairness perceptions when they are actively involved in the price-setting mechanism (Haws and Bearden 2006; Hinz et al. 2011; Huang et al. 2005; Richards et al. 2016) or feel that they have a higher level of control (Lee et al. 2011). Reasonable cost-justifications (Grewal et al. 2004) and framing formats across comparative transactions (Weisstein et al. 2013) can also mitigate consumers' negative fairness perception. Providing information about the pricing process also exerts a positive effect on consumer fairness perceptions (Choi and Mattila 2005; Kimes 1994). Although PDP implies that sellers have information about their consumers which enters price determination, academic discussion of the role of consumer data privacy and privacy concerns is lacking.

\section{PDP and privacy concerns}

The increasing collection and use of consumer data is raising consumer concerns about their privacy and data security (Martin et al. 2017). Indeed, information privacy is considered one of the most important ethical debates of the information age (Pavlou 2011). According to Smith et al. (1996), consumer concerns about information privacy can be classified into several dimensions: concerns about the collection of personal information, internal and external unauthorized secondary use of personal information, errors in personal information, and improper access to personal information.

PDP is a particularly strong source of consumer privacy concerns (Miller 2014). Sellers engage in massive collection of consumer data to sort consumers on their willingness to pay (Kochelek 2009). Consumers do not know what data sellers actually have on them (Turow et al. 2015), which violates human autonomy (Miller 2014) and raises consumer concerns about privacy (Smith et al. 1996). Odlyzko (2003) claims that privacy will continue to erode over time, as consumer data are critical to marketers' economic success. PDP is mostly non-transparent, which makes it seem delusive and manipulating to consumers (Nissenbaum 2009). Privacy concerns have been explored within the scope of targeted advertisement, personalized content, and service (for a comprehensive review, see Martin and Murphy 2017) but not PDP.

The context of online profiling shows that consumers with a higher level of general privacy concerns are less likely to accept customer profiling, meaning that they do not permit the creation of their customer profile (Awad and Krishnan 2006). Similarly, Miyazaki (2008) reveals a moderating effect of privacy concerns, such that consumers with higher privacy concerns show lower levels of trust, usage, and recommendation intentions as a result of detected cookie usage. Culnan and Armstrong (1999) find that consumer privacy concerns have a reduced moderating effect on the willingness to be profiled when consumers are explicitly told that fair procedures will be employed for managing their personal information.

In addition, privacy concerns can provoke different behavioral responses, such as the unwillingness to disclose data, preventive measures, lower trust and purchase intentions, or word-of-mouth initiation (Miyazaki 2008; Tsai et al. 2011). The type of collected information (Phelps et al. 2000), level of consumer control over data usage (Brandimarte et al. 2013), procedural fairness (Culnan and Armstrong 1999), and information transparency (Awad and Krishnan 2006) all affect consumers' privacy concerns.

\section{Conceptual background and hypotheses development}

\section{Dimensions of PDP}

This research extends the literature by considering two dimensions that help increase conceptual clarity on PDP: (1) the price individualization level and (2) the type of consumer-identifying segmentation base. These dimensions build a basis to systematically investigate the downstream effects of PDP on consumers' behavioral intentions.

The price individualization level captures the extent to which the pricing focuses on individual consumers. The level of price individualization can vary from individualconsumer prices to a fixed price for the entire customer base. PDP can encompass full PDP, implying individual prices across consumers depending on a variety of uniquely identifying characteristics (e.g., browsing history). However, 
PDP may also involve different prices for consumer segments, which represents segment pricing. Despite technological advances and data availability, data quality and sellers' abilities are often not sufficient to set fully individual prices (Aydin and Ziya 2009). In this case, sellers set segment prices for consumer segments classified by objectively observable characteristics (e.g., student discount).

Segmentation base is the second important dimension of PDP. As defined, PDP can depend on factors such as the IP address, location data, device type used, purchase or browsing history, or any other consumer-identifying characteristics. In PDP, the calculation is often not limited to one segmentation base. Instead, in many cases multiple segmentation bases are used to calculate price points for individuals or segments. For the sake of simplicity, we focus on two segmentation bases that are commonly used in the marketplace: location data and purchase history. Figure 1 illustrates the hypothesized relationships.

\section{Effect of the price individualization level}

Perceptions of price fairness refer to a consumer's judgment of his or her own price compared with the price of another reference party (Xia et al. 2004). In line with the general theoretical framework of equity and distributive justice theory (Adams 1965; Homans 1961), consumers judge the ratio of their in- and outputs to a transaction compared with the input-output ratio of other reference parties. If the comparative ratios are equal, consumers perceive a state of equity, which they inherently perceive as fair. By contrast, if the ratios differ in value, consumers perceive inequality, which they judge as unfair (Adams 1965). According to social comparison theory (Festinger 1954), comparisons with other customers are more salient and therefore induce the highest perceptions of unfairness in the case of a disadvantaged price difference (Ashworth and McShane 2012; Major and Testa 1989). When assessing their entitlement in a transaction, consumers compare themselves in particular with consumers who they perceive to be similar to themselves (Wood 1989).

In this vein, Mussweiler (2003) reports the existence of a similarity bias, which indicates that consumers take note of the similarity of the parties involved in comparison. If consumers find similarity, they tend to look out for other features that support this similarity. This process typically leads to an assimilation effect (Mussweiler 2003) that amplifies the perceived salience of outcome differences, which leads to higher perceptions of unfairness (Major and Testa 1989). By contrast, if consumers perceive dissimilarity in an initial assessment, they subsequently search for features that support this dissimilarity. This procedure typically leads to a contrast effect (Mussweiler 2003), such that consumers do not regard the other reference party as similar and therefore also rate the underlying transactions as dissimilar. Transaction dissimilarity provides consumers with an explanation for the outcome difference (Weisstein et al. 2013). Thus, a contrast effect leads to higher fairness perceptions.

In reference to these findings, the social comparison between individual consumers is more salient than that between consumer segments because consumers can judge

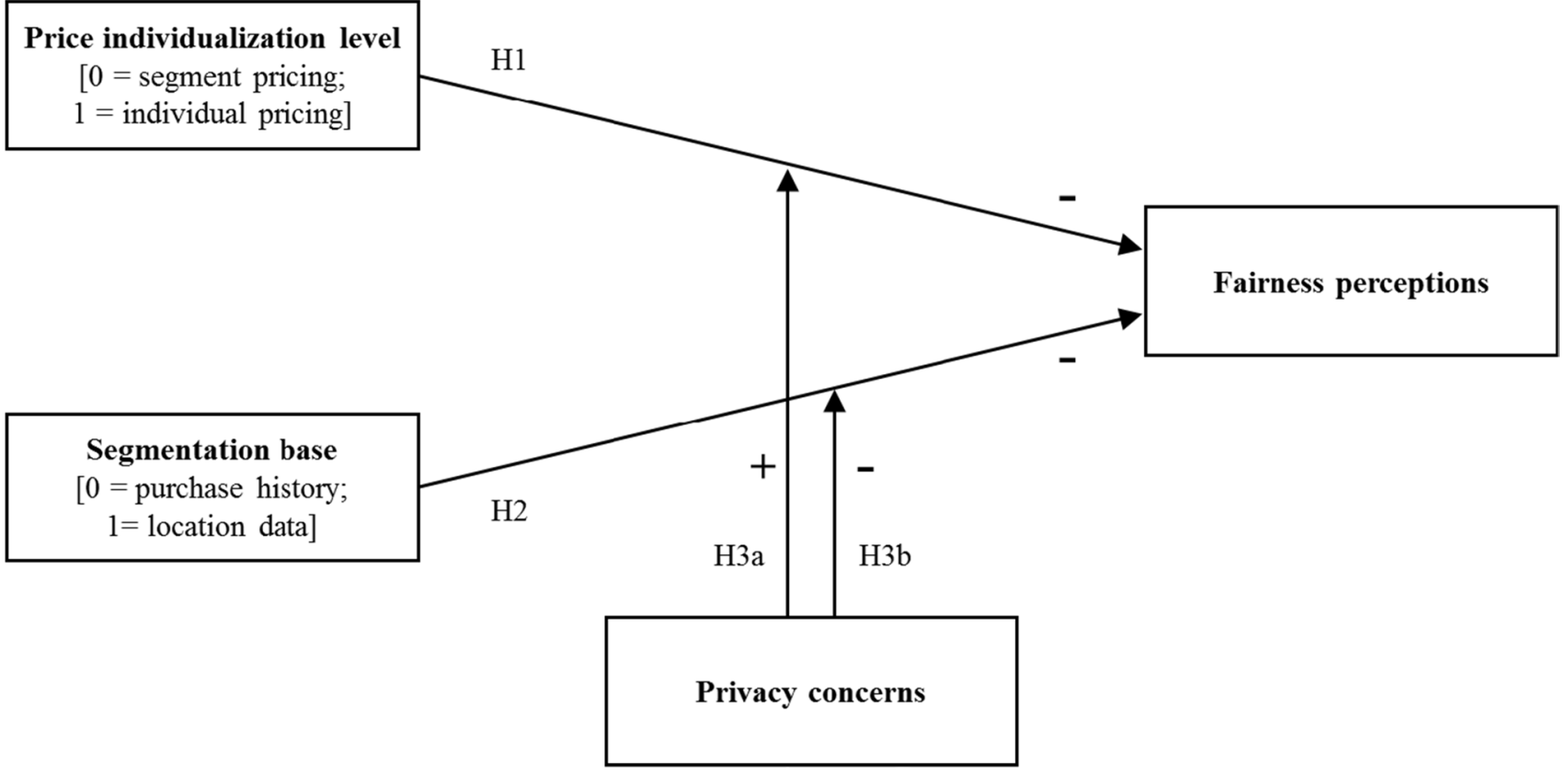

Fig. 1 Conceptual framework 
similarity/dissimilarity more easily. In the case of individual prices, consumers are more likely to find similarity between the self and the other consumer. Therefore, they perceive the transactions as also similar. In the face of similar transactions, an experienced price difference leads to the feeling of inequality and negative fairness perceptions. By contrast, a social comparison is more difficult between consumer segments because the comparative reference is a heterogeneous group of different consumers with varying characteristics. Therefore, consumers do not have a salient reference other on which they can base their comparison. Thus, consumers will more likely estimate dissimilarity between themselves and the segment and consequently judge price differences as more reasonable. We therefore propose the following:

H1 Consumers perceive individual prices as less fair than segment prices.

\section{Effect of the segmentation base}

Consumers' inferences about seller motives (Campbell 1999) and causal attributions as to who is responsible for a given outcome (Xia et al. 2004) also influence consumer fairness perceptions. Attribution theory (Heider 1958) suggests that consumers evaluate an unfavorable outcome as more negative if they attribute it to the seller (Vaidyanathan and Aggarwal 2003). By contrast, if consumers believe they are responsible (Folkes et al. 1987), have control over the outcome (Lee et al. 2011), or have the opportunity to participate in the price-setting process (Haws and Bearden 2006; Richards et al. 2016), they judge the pricing as fairer.

In addition, social norms serve as important guidance for consumers' fairness evaluations (Kahneman et al. 1986). Previous research has demonstrated the existence of several pricing norms (Maxwell 2002; Maxwell and Garbarino 2010). Such norms can develop over time and with increasing familiarity, until they often become the industry standard. Consumers evaluate a pricing strategy as fairer the more familiar they are with it (Wirtz and Kimes 2007) and the more it complies with norms (Choi and Mattila 2009; Garbarino and Maxwell 2010).

According to attribution theory, consumers perceive PDP as fairer if they can link the offered price to their own behavior. This applies to pricing based on consumer purchase history. In this case, consumers can make inferences from their purchase history to the price they received; thus, they have an explanation for the offered price. Moreover, pricing based on purchase history is a widespread pricing practice, which consumers evaluate as conforming to norms and therefore as fairer. By contrast, pricing based on location data is a new phenomenon, as the prerequisites (GPS data) have only recently become available. Therefore, consumers are not familiar with this pricing, nor is it possible for them to infer justifiable explanations such as internal attributions. Thus, we propose the following:

H2 Consumers perceive location-based pricing as less fair than purchase history-based pricing.

\section{Moderating role of privacy concerns}

An antecedent of privacy concerns is consumers' awareness that sellers collect information about them (Smith et al. 2011). Different types of consumer information can be distinguished, which causes different levels of privacy concerns (Phelps et al. 2000). Consumers tend to be more sensitive about and protective of financial data as well as personal identifiers and purchase-related information, while they are more likely to disclose demographic and lifestyle-related information about themselves (Nowak and Phelps 1992).

PDP involves highly personal and identifying consumer data for individual price determination. Consumers are especially sensitive to this type of data (Nowak and Phelps 1992). At the same time, consumers who are more sensitive tend to have higher privacy concerns. We therefore suggest that the higher the level of consumers' privacy concerns, the less fair they will evaluate individual prices resulting from PDP. By contrast, if PDP occurs on the level of segment pricing, less sensitive data are involved. Therefore, we claim that privacy concerns play a relatively minor role here. We thus argue that privacy concerns will intensify the proposed effect of the price individualization level on consumer fairness perceptions:

H3a Consumer privacy concerns strengthen the likelihood that consumers perceive individual prices as less fair than segment prices.

All segmentation bases used for PDP depend on highly personal data. As suggested, the higher consumers' privacy concerns, the more they are concerned about their privacy in general. Thus, we argue that consumers with high privacy concerns likely judge all types of PDP as unfair. Their perception will therefore not change depending on the segmentation base. Consequently, we propose that consumer privacy concerns mitigate the effect of varying segmentation bases on fairness perceptions:

H3b Consumer privacy concerns weaken the likelihood that consumers perceive location-based pricing as less fair than purchase history-based pricing. 


\section{Study 1}

This first empirical study investigates whether consumers perceive individual prices as less fair than segment prices (H1). We designed two written scenarios that used the same segmentation base but differed in the price individualization level. Thus, participants faced a situation of either individual pricing or segment pricing.

\section{Method}

The sample consisted of 91 students, who participated in the study in a computer lab of a European university (63.7\% male; average age: 23.52 [SD $=2.71]$ years). Study 1 employs one between-subjects factor (price individualization level: individual pricing vs. segment pricing). Participants read a scenario that asked them to imagine that they were buying a digital movie from an online media platform but later discovered that they either paid an individualconsumer price (individual pricing) or a price set for an entire consumer segment (segment pricing). The context of the purchase and usage of the digital movie excluded the existence of a transaction cost that otherwise could serve as an explanation for the experienced price difference. In the individualized pricing condition, participants were told that they were on holiday in a neighboring country, where they purchased the digital movie at an individualized price of $13.97 €$, which was based on the consumer's personal GPS data. The day after, they recognized that both a friend living in the neighboring country and a friend living in the participant's own country paid a lower price of $10.96 €$ for the same movie under the exact same purchase conditions, except that the friends watched the movie at their residual place (usual GPS data). Participants assigned to the segment pricing condition were told that they bought and watched the movie at home at a price of $13.99 €$. The next day, they recognized that a friend living in the neighboring country paid $10.99 €$, while a friend living in the same country as them paid the same price $(13.99 €)$ for the same movie under identical purchase conditions. The prices in this condition involved segment prices based on consumers' residual location data. Participants were told that the reference transaction involved the exact same purchase condition (same movie, time, and seller). Participants were randomly assigned to one of the two experimental conditions.

\section{Measurement}

After reading the scenario, participants were asked to evaluate their fairness perceptions. For the measurement, we adapted the following items from Martin et al. (2009) using a 7-point Likert scale: "The price you paid was fair," "The price you paid was reasonable," and "The price you paid was acceptable.” Cronbach's alpha was .89.

\section{Results}

To test the effect of price individualization on fairness perceptions, we conducted a $t$ test. The price individualization level presented the independent measure, while fairness perceptions were the dependent variable. The results indicate a marginally significant main effect for the price individualization level. As expected, participants who experienced individual prices showed lower fairness perceptions $(M=2.54, \mathrm{SD}=1.49)$ than those who experienced segment prices $(M=3.07, \mathrm{SD}=1.40 ; t(89)=1.747, p=.084)$, in support of $\mathrm{H} 1$.

\section{Discussion}

Study 1 provides evidence that the price individualization level influences consumers' fairness perceptions. We find that consumers had higher fairness perceptions when sellers engaged in segment pricing rather than individual pricing. However, we tested the impact of a varying price individualization level on fairness perceptions only for pricing based on location data; yet there are many more individualizing segmentation bases. Study 2 accounts for this and adds consumer purchase history as a second segmentation base.

\section{Study 2}

The second study has three aims. First, it strives to strengthen the generalizability and robustness of our results on the effect of the price individualization level on fairness perceptions by adding consumer purchase history as a second segmentation base (H1). Second, it investigates the effect of varying segmentation bases on fairness perceptions by examining whether consumers evaluate location-based pricing as less fair than purchase history-based pricing (H2). Third, the study aims to demonstrate the role of consumer privacy concerns in the effect on fairness perceptions (H3a, $\mathrm{H} 3 \mathrm{~b}$ ). To do so, we investigate whether privacy concerns intensify the likelihood that consumers perceive individual pricing as less fair than segment pricing (H3a). In addition, we assess whether consumers' privacy concerns reduce the likelihood that they judge location-based pricing as less fair than purchase history-based pricing (H3b).

\section{Method}

The sample consisted of 257 participants who were recruited over social networks to take part in an online experiment 
(41.6\% male; average age: $26.58[\mathrm{SD}=16.58]$ years). Study 2 employs a 2 (price individualization level: individual pricing vs. segment pricing) $\times 2$ (segmentation base: locationbased pricing vs. purchase history-based pricing) betweensubjects design. Participants were asked to imagine that they were buying a digital movie from an online media platform. The conditions of individual pricing and segment pricing based on location data were identical to those of Study 1. In the individual pricing condition based on purchase history, individual prices were the result of a consumer's individual purchase history. We used two reference transactions to underscore the individual price character. Participants were told that they bought the digital movie at a price of $13.99 €$ from a seller from which they have bought only two movies before. The day after their purchase, they recognized that a friend who has bought hundreds of movies at the respective seller before bought the movie at a price of $10.99 €$. Another friend who has bought five movies from this seller in the past was charged $13.29 €$ for the movie. Participants were informed that both friends purchased the movie under the same conditions as their own (same movie, time, and seller). In the segment pricing condition based on purchase history, participants faced a segment price depending on a threshold that divides consumers into two purchase history segments (e.g., light vs. heavy users). Participants were told that they bought the digital movie at a price of $13.99 €$ from a seller from which they only buy movies occasionally. Later on, they learned that a group of friends that buy more frequently at the seller bought the movie for $10.99 €$, while a group of friends buying similarly to them also purchased the movie for a price of $13.99 €$. Similar to the other conditions, participants were aware that the other reference groups bought the movie under identical conditions to their own. Participants were randomly assigned to one of the four experimental conditions.

\section{Measurement}

After reading the scenario, participants were asked questions about their fairness perceptions and level of privacy concerns. To assess fairness perceptions, we used the same scale as in Study 1. For the measurement of consumer privacy concerns, we used the items proposed by Martin et al. (2017): "I am sensitive to the way companies handle my personal information"; "It is important to keep my privacy intact from online companies"; "Personal privacy is very important, compared to other subjects"; and "I am concerned about threats to my personal privacy." To test for our hypothetical foundation, we asked participants to evaluate the extent to which they perceived their transaction as (dis) similar to the reference transactions. We adapted three items from Weisstein et al. (2013). All constructs were measured on 7-point Likert scales $(1=$ strongly disagree, $7=$ strongly agree). Cronbach's alpha for fairness perceptions was .84, .92 for privacy concerns, and .85 for perceived transaction (dis)similarity. Participants also responded to a manipulation check measure; they were asked to evaluate on which price individualization level the seller set the prices. Their answer was captured on a 7 -point scale $(1=$ individual-consumer pricing, $4=$ segment-specific pricing , $7=$ unspecificconsumer pricing).

\section{Results}

To test our manipulation, we conducted a two-way analysis of variance (ANOVA) with the price individualization level and the segmentation base as the independent variables and the manipulation check item as the dependent variable. There was only one significant main effect indicating that the manipulation was successful. The results show a significant difference $(F(1,253)=1.846, p<.001)$ between participants who saw the individual pricing scenario $(M=2.38$, $\mathrm{SD}=1.46)$ and those who saw the segment pricing scenario $(M=3.43, \mathrm{SD}=1.22)$.

To test $\mathrm{H} 1$ and $\mathrm{H} 2$, we employed a two-way ANOVA with price individualization level and segmentation base as independent measures and fairness perception as the dependent variable. The results show a marginally significant main effect for the price individualization level $(F(1,253)=2.999$, $p=.085)$. Participants rated individual prices as less fair $(M=2.72, \mathrm{SD}=1.27)$ than segment prices $(M=2.99$, $\mathrm{SD}=1.46$ ), in support of H1. Furthermore, the results show a significant difference in the perception of (dis)similarity between the individual pricing and segment pricing conditions $(\mathrm{F}(1,253)=4.02, p=.046)$. In the segment pricing condition, consumers perceived their transaction as less similar $(M=3.64, \mathrm{SD}=1.62)$ than in the individual pricing condition $(M=3.27, \mathrm{SD}=1.64)$, confirming the conceptual foundation of $\mathrm{H} 1$. We also find a significant main effect for the segmentation base $(F(1,253)=8.395, p=.004)$. Participants evaluated location-based pricing as significantly less fair $(M=2.62, \mathrm{SD}=1.38)$ than purchase history-based pricing $(M=3.10, \mathrm{SD}=1.30)$, in support of $\mathrm{H} 2$. The interaction effect is not significant $(F(1,253)=.135, p=.714)$.

To test $\mathrm{H} 3 \mathrm{a}$ and $\mathrm{H} 3 \mathrm{~b}$ on the moderation effects of privacy concerns, we executed two moderation analyses using model 1 of the PROCESS macro with 5,000 bootstrapped samples (Hayes 2018). Segment pricing and purchase history-based pricing served as baseline conditions. The results indicate that privacy concerns amplify the difference between individual pricing and segment pricing in terms of fairness perceptions ( $b 3=.207, p=.072$ ) (see Fig. 2). Participants with higher privacy concerns perceived individual pricing as less fair than segment pricing than consumers with lower privacy concerns, in support of H3a. The Johnson-Neyman technique shows that only participants with high privacy 


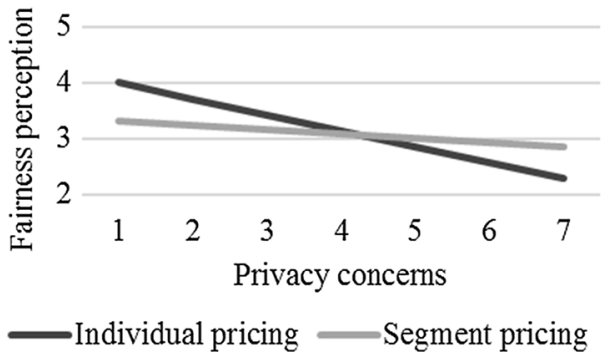

Fig. 2 Moderation effects of privacy concerns

concerns perceived individual pricing as significantly less fair than segment pricing. By contrast, privacy concerns weaken the effect of the segmentation base on fairness perceptions $(b 3=-.256, p=.024)$. Participants with high privacy concerns did not perceive location-based pricing as significantly less fair than purchase history-based pricing (see Fig. 2), in support of H3b. Table 2 gives detailed statistics. The regression coefficients $b_{1}$ and $b_{2}$ estimate the effect of the independent measures on fairness perceptions when privacy concerns are zero. Consequently, these coefficients do not have substantive interpretations.

\section{Discussion}

Study 2 corroborates the finding of Study 1 that the price individualization level affects consumers' fairness perceptions. We show that when sellers differentiate prices across individual consumers depending on personal information, consumers deem this pricing practice as less fair than when sellers set prices for different consumer segments based on less uniquely identifying information. In line with literature on social comparison, our results show that consumers in the segment pricing condition perceive their transaction as less similar to the reference transaction than consumers in the individual pricing condition, which provides an explanation

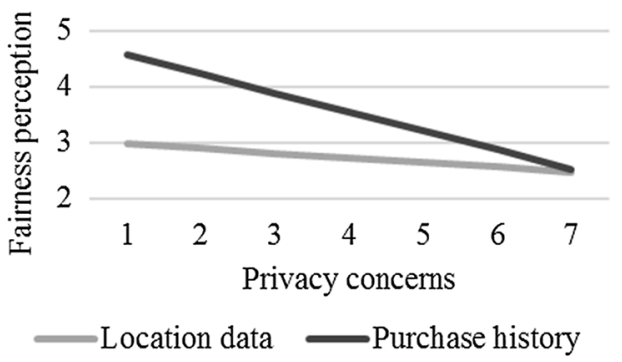

for the more favorable fairness perceptions of those participants (cf. Weisstein et al. (2013), who show that higher perceived transaction dissimilarity leads to higher fairness perceptions). In addition, this research finds evidence that the segmentation base also has an impact on consumers' fairness perceptions. That is, consumers have lower fairness perceptions for pricing based on location data than for pricing based on purchase history. This finding indicates that consumers feel more comfortable with the latter pricing, as it is a more common pricing practice. Moreover, Study $2 \mathrm{dem}-$ onstrates that consumer privacy concerns act as a moderating variable for the effects of both the price individualization level and the segmentation base on fairness perceptions. The effect of the price individualization level on fairness perceptions greatly depends on consumers' level of privacy concerns. Only consumers with high privacy concerns evaluate individual pricing as less fair than segment pricing. Consumers with low privacy concerns evaluate individual pricing as fairer than segment pricing. A possible explanation for this finding is the 'privacy calculus' (Dinev and Hart 2006). In line with rational choice theory, this privacy perspective suggests that consumers perform a risk-benefit analysis whenever they are in a situation in which it is necessary to weigh between protecting their information and giving up (at least some of) their privacy (Bulgurcu et al. 2010; Smith et al.

Table 2 Model coefficients for the moderation analyses in Study 2

\begin{tabular}{|c|c|c|c|c|c|}
\hline \multirow[b]{3}{*}{ Independent variables (H3a) } & \multicolumn{4}{|c|}{ Dependent variable } & \\
\hline & \multicolumn{4}{|c|}{ Fairness perceptions } & \\
\hline & Coeff. & & SE & $t$ value & \\
\hline Price individualization level (PIL) & $b_{1}$ & -.8963 & .6304 & -1.4218 & $\mathrm{R}^{2}=.0586$ \\
\hline Privacy concerns & $b_{2}$ & $-.2841 * * *$ & .0815 & -3.4861 & \\
\hline \multirow[t]{2}{*}{ PIL $\times$ privacy concerns } & $b_{3}$ & $.2069^{*}$ & .1146 & 1.8059 & \\
\hline & \multicolumn{4}{|c|}{ Fairness perceptions } & \\
\hline Independent variables $(\mathrm{H} 3 \mathrm{~b})$ & Coeff. & & SE & $t$ value & \\
\hline Segmentation base & $b_{1}$ & $1.8446 * * *$ & .6034 & 3.0570 & $\mathrm{R}^{2}=.0908$ \\
\hline Privacy concerns & $b_{2}$ & -.0828 & .0796 & -1.0400 & \\
\hline Segmentation base $\times$ privacy concerns & $b_{3}$ & $-.2561 * *$ & .1130 & -2.2668 & \\
\hline
\end{tabular}

$* * * p<0.01, * * p<0.05, * p<0.1$ 
2011). Risks of a potential loss of data privacy, data fraud, or other negative consequences from disclosing one's personal information can heighten consumer privacy concerns (Zhu et al. 2017). Benefits are the positive outcomes that consumers receive from giving their personal data, such as enhanced services or customized offers (Chellappa and Sin 2005). Consumers with low privacy concerns have lower risk perceptions of individual pricing, which explains why they might be more receptive to the potential benefits and are more positive toward this pricing. Indeed, individual pricing can be beneficial for some consumers. Referring back to the scenarios, with individual pricing a loyal customer who has already bought many movies can achieve a substantial lower price than a new customer. Low privacy concerns could shift the privacy calculus trade-off, so that this benefit is more evident to those consumers, resulting in more positive fairness perceptions. Furthermore, we revealed that privacy concerns mitigate the effect of the segmentation base on consumer fairness perceptions. Consumers with high privacy concerns do not perceive location-based pricing as less fair than purchase history-based pricing; rather, they perceive all pricing types as equally (un)fair.

\section{General discussion}

\section{Theoretical implications}

Previous studies have treated PDP as uniform pricing, without taking into account that different degrees of price individualization (e.g., individual prices vs. segment prices) or different underlying segmentation criteria (e.g., location data vs. purchase history) may influence consumer perceptions differently. The current research enriches literature by suggesting a new conceptualization of PDP-namely, it distinguishes two dimensions that determine PDP: the price individualization level and the segmentation base. It also provides empirical support for this twofold perspective. In particular, our research discusses a higher price individualization level than previous research, which has mainly examined consumer perceptions of interpersonal price discrimination at the price individualization level of consumer segments (Garbarino and Maxwell 2010; Grewal et al. 2004; Haws and Bearden 2006; Huang et al. 2005; Lii and Sy 2009; Wu et al. 2012). Yet it also enriches the discussion on interpersonal price discrimination, such as pricing based on purchase time or purchase quantity (Garbarino and Maxwell 2010; Grewal et al. 2004; Lii and Sy 2009), by elaborating on geographic location and purchase history as segmentation criteria.

More important, this research goes beyond previous studies by comparing different forms of interpersonal price discrimination in one study. In doing so, it extends the research of Huang et al. (2005) and Wu et al. (2012), who investigate different consumer-specific segmentation bases at a time. However, in contrast with these studies, we also consider the price individualization level (i.e., fully individual prices). To our knowledge, Krämer et al. (2018) are the only researchers to implicitly include both individual and segment pricing in the form of different segmentation criteria; yet they do not elaborate on different segmentation bases simultaneously in a full factorial design. Thus, consumer perceptions cannot be clearly assigned to either the price individualization level or the segmentation criterion. Our research closes these gaps and investigates both criteria to show the interactions. The results of our two empirical studies indicate that both dimensions have significant effects on consumer fairness perceptions independent of each other.

Finally, this article is the first to empirically investigate the role of privacy concerns in the context of PDP. It follows arguments of Miller (2014) and Odlyzko (2003), who conceptually elaborate on consumers' increasing concerns about the collection and use of personal information for pricing. The findings reveal that privacy concerns intensify the likelihood that consumers perceive individual pricing as less fair than segment pricing. In addition, privacy concerns weaken the likelihood that consumers evaluate location-based pricing as less fair than purchase history-based pricing.

\section{Managerial implications}

Managers need to be aware that individual pricing leads to higher ethical concerns than segment pricing. However, we assume that managers are primarily interested in using individual pricing for revenue reasons. We thus offer important recommendations based on our findings that can mitigate consumer concerns. First, we suggest that managers provide consumers with additional information that indicates how certain components play into price setting. For example, they could indicate that consumers who register on the web page, who qualify as loyal customers, who are students, and so on, receive price advantages. This information may help consumers recognize that those who paid another price possibly deserved that price because they did meet certain requirements. The provision of such pricing components could make up for price differences between individual consumers and make consumers react less negatively when learning that another consumer received another price. Second, we propose the possibility of price framing. When managers use different price formats, price comparisons between reference transactions are more difficult, making price differences less salient and therefore resulting in a positive effect on fairness perceptions. Weisstein et al. (2013) show that managers can use different price formats (e.g., percent off the price; $\$$ off the price) to frame the fairness perceptions of PDP. 
We also recommend that managers consider ways to give consumers the illusion of control over the price they finally pay. When consumers believe they can actively influence the price they pay (e.g., by adjusting their purchase frequency), they judge the pricing as fairer. Consumers also need to be aware of the prices they pay. In line with research on price transparency, we assume that consumers react negatively if prices change quickly or if they are surprised by a price they did not expect (Robbert and Roth 2018). Finally, our results reveal that privacy concerns intensify the likelihood that consumers perceive individual pricing as less fair. To overcome these privacy concerns, managers should communicate a privacy policy that includes how they process consumer data. Building trust and reliable relationships but also highlighting the potential benefits of pricing which is based on consumer characteristics may help managers to reduce privacy concerns and thus increase consumer acceptance of PDP (Chellappa and Sin 2005). Overall, despite the tempting opportunity to enhance profits, PDP holds a significant risk for sellers. Managers should therefore carefully consider this pricing, as negative fairness perceptions go often hand in hand with a decrease in consumer satisfaction (Oliver and Swan 1989) and other negative behavioral consequences (Xia et al. 2004).

\section{Future research directions}

PDP is being facilitated by new information technologies. Data collection and big data analytics will continue to influence market developments in the future. Therefore, we suggest several avenues for future research. While other pricing conditions apply online than offline, future research should examine consumer fairness perceptions from the proposed dimensions in an offline context. Privacy concerns are most notably observed in the online environment, as indicators that ensure sellers' trustworthiness or reputation are often less reliable. Thus, future analyses on the moderation effects of privacy concerns would be particularly interesting in an offline setting. In this article, we simplified the idea of individual PDP by assuming implementation of individual prices based on one segmentation base. In reality, often more information plays into the price determination of individual prices. Future research should examine whether the number of segmentation criteria used for price setting affects consumer perceptions. Moreover, the focus of our research was on disadvantaged PDP, as consumers faced a lower price than the reference party. Future research could assess the effects of advantaged PDP. We also examined location data and purchase history as potential segmentation bases. A future research opportunity is to investigate other segmentation bases and their effects. Given the unexplored role of privacy concerns in the pricing context, our moderation analysis focused on consumer privacy concerns. Researchers could investigate other potential moderators, such as consumer trust or loyalty status.

Acknowledgements Open Access funding provided by Projekt DEAL.

Open Access This article is licensed under a Creative Commons Attribution 4.0 International License, which permits use, sharing, adaptation, distribution and reproduction in any medium or format, as long as you give appropriate credit to the original author(s) and the source, provide a link to the Creative Commons licence, and indicate if changes were made. The images or other third party material in this article are included in the article's Creative Commons licence, unless indicated otherwise in a credit line to the material. If material is not included in the article's Creative Commons licence and your intended use is not permitted by statutory regulation or exceeds the permitted use, you will need to obtain permission directly from the copyright holder. To view a copy of this licence, visit http://creativecommons.org/licenses/by/4.0/.

\section{References}

Abrate, G., J.L. Nicolau, and G. Viglia. 2019. The impact of dynamic price variability on revenue maximization. Tourism Management 74: 224-233.

Adams, J.S. 1965. Inequity in social exchange. In Advances in experimental social psychology, vol. 2, ed. L. Berkowitz, 267-299. New York: Academic Press.

Ashworth, L., and L. McShane. 2012. Why do we care what others pay? The effect of other consumers' prices on inferences of seller (dis) respect and perceptions of deservingness violation. Journal of Retailing 88 (1): 145-155.

Awad, N.F., and M.S. Krishnan. 2006. The personalization privacy paradox: An empirical evaluation of information transparency and the willingness to be profiled online for personalization. MIS Quarterly 30 (1): 13-28.

Aydin, G., and S. Ziya. 2009. Personalized dynamic pricing of limited inventories. Operations Research 57 (6): 1523-1531.

Bolton, L.E., L. Warlop, and J.W. Alba. 2003. Consumer perceptions of price (un)fairness. Journal of Consumer Research 29 (4): $474-491$.

Borgesius, F.Z., and J. Poort. 2017. Online price discrimination and EU data privacy law. Journal of Consumer Policy 40 (3): 347-366.

Brandimarte, L., A. Acquisti, and G. Loewenstein. 2013. Misplaced confidences: Privacy and the control paradox. Social Psychological and Personality Science 4 (3): 340-347.

Bulgurcu, B., H. Cavusoglu, and I. Benbasat. 2010. Information security policy compliance: An empirical study of rationality-based beliefs and information security awareness. MIS Quarterly 34 (3): 523-548.

Campbell, M.C. 1999. "Why did you do that?" The important role of inferred motive in perceptions of price fairness. Journal of Product \& Brand Management 8 (2): 145-153.

Carroll, K., and D. Coates. 1999. Teaching price discrimination: Some clarification. Southern Economic Journal 66 (2): 466-467.

Chellappa, R.K., and R.G. Sin. 2005. Personalization versus privacy: An empirical examination of the online consumer's dilemma. Information Technology and Management 6 (2-3): 181-202.

Choi, S., and A.S. Mattila. 2004. Hotel revenue management and its impact on customers' perceptions of fairness. Journal of Revenue and Pricing Management 2 (4): 303-314.

Choi, S., and A.S. Mattila. 2005. Impact of information on customer fairness perceptions of hotel revenue management. Cornell Hotel and Restaurant Administration Quarterly 46 (4): 444-451. 
Choi, S., and A.S. Mattila. 2009. Perceived fairness of price differences across channels: The moderating role of price frame and norm perceptions. Journal of Marketing Theory and Practice 17 (1): $37-48$

Choudhary, V., A. Ghose, T. Mukhopadhyay, and U. Rajan. 2005. Personalized pricing and quality differentiation. Management Science 51 (7): 1120-1130.

Clifford, S. 2012. Shopper alert: Price may drop for you alone. New York Times, August 9, https://www.analyticbridge.datascienc ecentral.com/profiles/blogs/shopper-alert-price-may-drop-foryou-alone-newyorktimes.

Culnan, M.J., and P.K. Armstrong. 1999. Information privacy concerns, procedural fairness, and impersonal trust: An empirical investigation. Organization Science 10 (1): 104-115.

DeAmicis, C. 2015 Here's why new competitors can't do what Hotel Tonight does. January 27, https://gigaom.com/2015/01/27/ heres-why-new-competitors-cant-do-what-hotel-tonight-does/ Accessed 8 Oct 2018

Dhar, S.K., and S.J. Hoch. 1996. Price discrimination using in-store merchandising. Journal of Marketing 60 (1): 17-30.

Dinev, T., and P. Hart. 2006. An extended privacy calculus model for e-commerce transactions. Information Systems Research 17 (1): 61-80.

Festinger, L. 1954. A theory of social comparison processes. Human Relations 7 (2): 117-140.

Folkes, V.S., S. Koletsky, and J.L. Graham. 1987. A field study of causal inferences and consumer reaction: The view from the airport. Journal of Consumer Research 13 (4): 534-539.

Garbarino, E., and O.F. Lee. 2003. Dynamic pricing in internet retail: Effects on consumer trust. Psychology \& Marketing 20 (6): 495-513.

Garbarino, E., and S. Maxwell. 2010. Consumer response to normbreaking pricing events in e-commerce. Journal of Business Research 63 (9/10): 1066-1072.

Grewal, D., D.M. Hardesty, and G.R. Iyer. 2004. The effects of buyer identification and purchase timing on consumers' perceptions of trust, price fairness, and repurchase intentions. Journal of Interactive Marketing 18 (4): 87-100.

Haws, K.L., and W.O. Bearden. 2006. Dynamic pricing and consumer fairness perceptions. Journal of Consumer Research 33 (3): 304-311.

Hayes, A.F. 2018. Introduction to mediation, moderation, and conditional process analysis: A regression-based approach. New York: Guilford Press.

Heider, F. 1958. The psychology of interpersonal relations. New York: Wiley.

Hinz, O., I.H. Hann, and M. Spann. 2011. Price discrimination in e-commerce? An examination of dynamic pricing in name-yourown price markets. MIS Quarterly 35 (1): 81-98.

Homans, G.C. 1961. Human behavior: Its elementary forms. New York: Brace and World Inc.

Huang, J.H., C.T. Chang, and C.Y.H. Chen. 2005. Perceived fairness of pricing on the internet. Journal of Economic Psychology 26 (3): 343-361.

Kahneman, D., J.L. Knetsch, and R.H. Thaler. 1986. Fairness and the assumptions of economics. Journal of Business 59 (4): 285-300.

Kalyanaram, G., and R.S. Winer. 1995. Empirical generalizations from reference price research. Marketing Science 14 (3): G161-G169.

Kimes, S.E. 1994. Perceived fairness of yield management: Applying yield-management principles to rate structures is complicated by what consumers perceive as unfair practices. Cornell Hotel and Restaurant Administration Quarterly 35 (1): 22-29.

Kochelek, D.M. 2009. Data mining and antitrust. HARV. J.L. \& TECH 22: $515-535$
Krämer, A., M. Friesen, and T. Shelton. 2018. Are airline passengers ready for personalized dynamic pricing? A study of German consumers. Journal of Revenue and Pricing Management 17 (2): $115-120$.

Lee, S., A. Illia, and A. Lawson-Body. 2011. Perceived price fairness of dynamic pricing. Industrial Management \& Data Systems 111 (4): 531-550.

Lichtenstein, D.R., P.H. Bloch, and W.C. Black. 1988. Correlates of price acceptability. Journal of Consumer Research 15 (2): $243-252$.

Lii, Y.S., and E. Sy. 2009. Internet differential pricing: Effects on consumer price perception, emotions, and behavioral responses. Computers in Human Behavior 25 (3): 770-777.

Major, B., and M. Testa. 1989. Social comparison processes and judgments of entitlement and satisfaction. Journal of Experimental Social Psychology 25 (2): 101-120.

Martin, K.D., A. Borah, and R.W. Palmatier. 2017. Data privacy: Effects on customer and firm performance. Journal of Marketing 81 (1): 36-58

Martin, K.D., and P.E. Murphy. 2017. The role of data privacy in marketing. Journal of the Academy of Marketing Science 45 (2): $135-155$.

Martin, W.C., N. Ponder, and J.E. Lueg. 2009. Price fairness perceptions and customer loyalty in a retail context. Journal of Business Research 62 (6): 588-593.

Mattioli, D. 2012. On Orbitz, Mac users steered to pricier hotels. Wall Street Journal, August 23, https://www.wsj.com/articles/SB100 01424052702304458604577488822667325882.

Maxwell, S. 2002. Rule-based price fairness and its effect on willingness to purchase. Journal of Economic Psychology 23 (2): 191-212.

Maxwell, S., and E. Garbarino. 2010. The identification of social norms of price discrimination on the internet. Journal of Product \& Brand Management 19 (3): 218-224.

Mazumdar, T., S.P. Raj, and I. Sinha. 2005. Reference price research: Review and propositions. Journal of Marketing 69 (4): 84-102.

Miller, A.A. 2014. What do we worry about when we worry about price discrimination-The law and ethics of using personal information for pricing. Journal of Technology Law \& Policy 19: 41-104.

Miyazaki, A.D. 2008. Online privacy and the disclosure of cookie use: Effects on consumer trust and anticipated patronage. Journal of Public Policy \& Marketing 27 (1): 19-33.

Monroe, K.B. 1973. Buyers' subjective perceptions of price. Journal of Marketing Research 10 (1): 70-80.

Mussweiler, T. 2003. Comparison processes in social judgment: Mechanisms and consequences. Psychological Review 110 (3): 472-489.

Narasimhan, C. 1984. A price discrimination theory of coupons. Marketing Science 3 (2): 128-147.

Nissenbaum, H. 2009. Privacy in context: Technology, policy, and the integrity of social life. Stanford: Stanford University Press.

Nowak, G.J., and J.E. Phelps. 1992. Understanding privacy concerns: An assessment of consumers' information-related knowledge and beliefs. Journal of Direct Marketing 6 (4): 28-39.

Odlyzko, A. 2003. Privacy, economics, and price discrimination on the internet. In Proceedings of the 5th international conference on electronic commerce; 30 September-3 October, Pittsburgh, Pennsylvania, New York, ACM, 355-366.

Oliver, R.L., and J.E. Swan. 1989. Consumer perceptions of interpersonal equity and satisfaction in transactions: A field survey approach. Journal of Marketing 53 (2): 21-35.

Pavlou, P.A. 2011. State of the information privacy literature: Where are we now and where should we go? MIS Quarterly 35 (4): 977-988. 
Phelps, J., G. Nowak, and E. Ferrell. 2000. Privacy concerns and consumer willingness to provide personal information. Journal of Public Policy \& Marketing 19 (1): 27-41.

Pigou, A.C. 1929. The economics of welfare. London: Macmillan.

Richards, T.J., J. Liaukonyte, and N.A. Streletskaya. 2016. Personalized pricing and price fairness. International Journal of Industrial Organization 44: 138-153.

Robbert, T., and S. Roth. 2018. The importance of transparency signals in à la carte pricing. Journal of Revenue and Pricing Management 17 (1): $32-40$.

Smith, H.J., T. Dinev, and H. Xu. 2011. Information privacy research: An interdisciplinary review. MIS Quarterly 35 (4): 989-1016.

Smith, H.J., S.J. Milberg, and S.J. Burke. 1996. Information privacy: Measuring individuals' concerns about organizational practices. MIS Quarterly 20 (2): 167-196.

Streitfeld, D. 2000. On the web price tags blur: What you pay could depend on who you are. The Washington Post, September 27, https ://www.washingtonpost.com/archive/politics/2000/09/27/on-theweb-price-tags-blur/14daea51-3a64-488f-8e6b-c1a3654773da/.

Thisse, J.F., and X. Vives. 1988. On the strategic choice of spatial price policy. The American Economic Review 78 (1): 122-137.

Tsai, J.Y., S. Egelman, L. Cranor, and A. Acquisti. 2011. The effect of online privacy information on purchasing behavior: An experimental study. Information Systems Research 22 (2): 254-268.

Turow, J., M. Hennessy, and N. Draper. 2015. The tradeoff fallacy: How marketers are misrepresenting American consumers and opening them up to exploitation. https://ssrn.com/abstract $=2820060$.

Vaidyanathan, R., and P. Aggarwal. 2003. Who is the fairest of them all? An attributional approach to price fairness perceptions. Journal of Business Research 56 (6): 453-463.

Valentino-DeVries, J., J. Singer-Vine, and A. Soltani. 2012. Websites vary prices, deals based on users' information. Wall Street Journal 10: 60-68.

Varian, H.R. 1989. Price discrimination. In Handbook of industrial organization, ed. R. Schmalensee, M. Armstrong, R.D. Willig, and R.H. Porter, 597-654. Amsterdam: Elsevier.

Viglia, G., and G. Abrate. 2014. How social comparison influences reference price formation in a service context. Journal of Economic Psychology 45: 168-180.

Wallheimer, B. 2018 Are you ready for personalized pricing? 26 February, https://review.chicagobooth.edu/marketing/2018/article/areyou-ready-personalized-pricing. Accessed 22 July 2019.
Weisstein, F.L., K.B. Monroe, and M. Kukar-Kinney. 2013. Effects of price framing on consumers' perceptions of online dynamic pricing practices. Journal of the Academy of Marketing Science 41 (5): 501-514.

Wirtz, J., and S.E. Kimes. 2007. The moderating role of familiarity in fairness perceptions of revenue management pricing. Journal of Service Research 9 (3): 229-240.

Wittman, M.D., and P.P. Belobaba. 2017. Personalization in airline revenue management: Heuristics for real-time adjustment of availability and fares. Journal of Revenue and Pricing Management 16 (4): 376-396.

Wood, J.V. 1989. Theory and research concerning social comparisons of personal attributes. Psychological Bulletin 106 (2): 231-248.

Wu, C.C., Y.F. Liu, Y.J. Chen, and C.J. Wang. 2012. Consumer responses to price discrimination: Discriminating bases, inequality status, and information disclosure timing influences. Journal of Business Research 65 (1): 106-116.

Xia, L., K.B. Monroe, and J.L. Cox. 2004. The price is unfair! A conceptual framework of price fairness perceptions. Journal of Marketing 68 (4): 1-15.

Zhu, H., C.X. Ou, W.J.A.M. Van den Heuvel, and H. Liu. 2017. Privacy calculus and its utility for personalization services in e-commerce: An analysis of consumer decision-making. Information \& Management 54 (4): 427-437.

Publisher's Note Springer Nature remains neutral with regard to jurisdictional claims in published maps and institutional affiliations.

Anna Priester is a Research Associate at the Department of Marketing at the TU Kaiserslautern, Germany. Her research focuses on personalized pricing, dynamic pricing, and micropayments.

Thomas Robbert is a Postdoctoral Research Associate at the Department of Marketing at the TU Kaiserslautern, Germany. His research deals with behavioral pricing and services marketing.

Stefan Roth is Professor of Marketing at the TU Kaiserslautern, Germany. His research focuses on price and negotiation management, services marketing, and marketing theory. 